\title{
ANÁLISE DA GESTÃO PRIVADA DE RECURSOS PÚBLICOS A PARTIR DA CONTEXTUALIZAÇÃO HISTÓRICA DAS POLÍTICAS PÚBLICAS DE SAÚDE NO BRASIL
}

\author{
ANALYSIS OF THE PRIVATE MANAGEMENT OF PUBLIC RESOURCES \\ BASED ON THE HISTORICAL CONTEXTUALIZATION OF PUBLIC HEALTH \\ POLICIES IN BRAZIL
}

${ }^{1}$ Elda Coelho de Azevedo Bussinguer

${ }^{2}$ Shayene Machado Salles

\section{RESUMO}

Propõe-se a adentrar o contexto das transformações resultantes da hegemonia do sistema capitalista para questionar, no âmbito da relação público-privado, as consequências da gestão privada de recursos para a concepção de saúde que tem orientado as políticas públicas de saúde no país. Promover-se-á um aprofundamento teórico em movimentos historicamente demarcados, do período militar à República democrática em 1988, tendo em vista a distinção da concepção de saúde que alicerçou o desenvolvimento das políticas em cada lapso temporal. Esclarecer-se-á a relação entre o contexto sócio-político em que as políticas foram concebidas e a orientação contemporânea das mesmas rumo às tendências privatistas.

Palavras-chave: Políticas públicas de saúde, Relação público-privado, Gestão privada de recursos públicos

\begin{abstract}
The purpose is to study the changes that resulted of the capitalist system hegemony to question, in the context of public-private relationships, the consequences of private management on the idea of health that has guided public health policies in the country. A theoretical deepening on historically demarcated movements will be conducted, from the Military Regime to the Democratic Republic in 1988, keeping in mind the distinction of the idea of health in each time frame. The contexts in which these policies were created and the orientation of these policies toward private tendencies will be clarified.
\end{abstract}

Keywords: Public health policies, Public-private relationships, Private management of public resources

\footnotetext{
${ }^{1}$ Doutora em Bioética pela Universidade de Brasília, UnB. Professora da Faculdade de Direito de Vitória, FDV, Espírito Santo (Brasil). E-mail: elda.cab@gmail.com

${ }^{2}$ Mestrado em andamento em Direitos e Garantias Fundamentais na Faculdade de Direito de Vitória - FDV, Espírito Santo (Brasil). E-mail: shayenemachado@gmail.com
} 


\section{INTRODUÇÃO}

Problematizar o conhecimento em saúde, numa conjuntura pautada em propostas políticas estimuladoras da abertura do mercado ao capital estrangeiro, da privatização de empresas e de serviços públicos, bem como da desregulamentação e flexibilização das relações de trabalho, implica em situar sua práxis no dinâmico contexto sociopolítico que a sustenta, sobretudo por já não ser possível ignorar as influências do capital ao modo como as políticas de saúde, no Brasil, tem se desenvolvido ao longo dos últimos anos.

Para demonstrar as mudanças vivenciadas no fenômeno da saúde e, mais especificamente, no âmbito das políticas públicas, torna-se indispensável o aprofundamento na dinâmica de construção social que caracterizaram os movimentos históricos no processo de desenvolvimento das políticas públicas de saúde no Brasil. Para tanto, foram realizados estudos descritivos mediante pesquisa bibliográfica acerca do desenvolvimento das políticas públicas no Brasil. A partir do levantamento bibliográfico realizado, promover-se-á uma análise do contexto contemporâneo, caracterizado pela gestão privada de recursos públicos, à luz dos movimentos históricos viabilizadores da elucidação do processo de desenvolvimento das políticas públicas de saúde no Brasil.

Dito isto, cumpre esclarecer que a pesquisa encontra-se estruturalmente alicerçada pelas seguintes hipótese/ premissas: 1) No âmbito da saúde, a análise teórica dos principais movimentos históricos, do período colonial à república democrática constituída em 1988, é imprescindível para a contextualização de uma concepção democratizada das políticas públicas de saúde no Brasil; 2) É possível relacionar o contexto sócio-político em que as políticas foram concebidas e a orientação contemporânea das mesmas rumo às tendências privatistas. 3) A gestão privada de recursos públicos, por meio das Organizações Sociais de Saúde, representa uma tendência resultante da hegemonia do sistema capitalista no âmbito da relação público-privado, repercutindo, diretamente, na concepção de saúde que tem orientado as políticas públicas de saúde no Brasil.

Por razões metodológicas, os movimentos históricos que foram objeto analítico deste estudo são os seguintes: a) do período getulista ao golpe de 1964; b) do golpe de 1964 à reforma sanitária; c) do movimento da reforma sanitária, cuja emergência se deu como resposta à crise de um modelo de saúde, à realidade contemporânea. 
A par dessas considerações preliminares, convém esclarecer que o objetivo primacial deste estudo consiste em analisar o contexto das transformações resultantes da hegemonia do sistema capitalista para questionar, no âmbito da relação público-privado, as consequências da gestão privada de recursos públicos para a concepção de saúde que, contemporaneamente, tem orientado as políticas públicas de saúde no Brasil. Nesse sentido, afirma-se que a temática objeto deste artigo representa um dos desafios inerentes a contextualização das políticas públicas na democracia brasileira não consolidada.

\section{UMA CONTEXTUALIZAÇÃO PRELIMINAR DO HISTÓRICO DO DESENVOLVIMENTO DAS POLÍTICAS PÚBLICAS DE SAÚDE NO BRASIL: DO PERÍODO COLONIAL À DÉCADA DE 1930}

A premissa fundamental da qual se parte consiste na constatação de que a compreensão do processo histórico de construção da acepção de saúde, e de sua ampliação, no Brasil assume sua relevância por estar diretamente atrelada ao modo como as práticas sanitárias e as políticas públicas, visando à promoção da saúde, irão se desenvolver, decorrendo daí a importância desse esforço histórico para o avanço das reflexões atinentes ao objetivo central deste estudo.

No Brasil, pode-se dizer que o marco histórico representativo do início da regulamentação das práticas de saúde ocorreu, em 1808, com a vinda da família real para o país, fato que inaugurou a preocupação da Coroa Portuguesa com a saúde dos imigrantes que viriam integrar a mão-de-obra que alicerça a manutenção da atividade econômica desenvolvida (COTTA et al., 2013, p. 88-89). Nesse período, a diversidade étnica que caracterizava os povos que habitavam o Brasil (negros, índios, imigrantes europeus, portugueses) implicava na coexistência de tradições culturais plurais que, no âmbito da aplicação de serviços de saúde, exprimiam práticas próprias no tratamento das doenças (COTTA et al., 2013, p. 88) (ESCOREL; TEIXEIRA, 2012, p. 279-322).

A princípio, o interesse na estruturação de um projeto de institucionalização do setor saúde nasce atrelado à necessidade de atender as necessidades da elite dominante, isto é, da aristocracia portuguesa, assegurando a manutenção do status quo, mediante a instrumentalização de medidas capazes de proporcionar respostas às doenças que acometiam a sociedade no século XIX, tais como a varíola e a febre amarela (COTTA et al., 2013, p. 89) (ESCOREL, TEIXEIRA, 2012, p. 279-322). No Brasil colonial, a percepção 
embrionária apresentada no âmbito da saúde reservava à ação pública um espaço restrito à implementação de práticas como (COTTA et al., 2013, p. 89-90):

- proteção e saneamento das cidades, principalmente as portuárias, responsáveis pela comercialização e circulação dos produtos exportados;

- $\quad$ fiscalização do exercício da medicina;

- $\quad$ atendimento às camadas da população com maior poder aquisitivo;

- controle das doenças/epidemias que pudessem afetar a principal atividade econômica da época (economia agroexportadora cafeeira);

- avanço das biotecnologias para adoção de práticas mais eficazes no controle das moléstias (criação das vacinas).

Nota-se, portanto, que o proveito mercantil, decorrente circulação de mercadorias, e a consequente importância de promover o controle das epidemias sociais integravam um papel relevante para o padrão de conhecimento em saúde daquela época, ao qual era atribuído uma concepção restritiva necessariamente vinculada ao saneamento das cidades, à cura e ao tratamento de doenças.

Apenas com a proclamação da República, ocorrida em 1889, é que a saúde passa ser assumidamente uma política de Estado, embora essa atuação estatal permaneça fundada no viés mercantil, uma vez que decorrente da constatação de que "[...] as epidemias que se alastravam entre os trabalhadores, devido às péssimas condições de saneamento, prejudicavam o crescimento da economia" (COTTA et al., 2013, p. 90). As ações direcionadas à saúde, promovidas pela política sanitarista do governo de Rodrigues Alves, nos anos de 1902 e 1903, foram responsáveis pela contenção de graves epidemias (febre amarela, peste bubônica e varíola), bem como pela implementação de medidas de saneamento e de urbanização da cidade do Rio de Janeiro (COTTA et al., 2013, p. 91). Nesse período, a Diretoria Geral de Saúde Pública (DGSP), criada em 1897, era coordenada pelo médico- sanitarista Oswaldo Cruz, o qual, dentre outras medidas implementadas durante a sua gestão, ficou historicamente reconhecimento como o agente intelectual que incitou a denominada "Revolta da Vacina", movimento que se insurgiu contra o decreto presidencial da "Lei da vacinação obrigatória", numa clara desconsideração da autonomia e da subjetividade dos indivíduos destinatários da medida (COTTA et al., 2013, p. 91-92).

Ademais, o discurso de higienização urbana que respaldava a política de vacinação obrigatória, proposta por Oswaldo Cruz, atribuía à saúde uma conotação policialesca alicerçada na necessidade de vigilância sanitária, a qual, embora, em tese, fosse destinada à 
todos, restringia-se às zonas urbanas produtivas (COTTA et al., 2013, p. 92) (ESCOREL; TEIXEIRA, 2012, p. 279-322).

A ampliação das ações estatais no que diz respeito ao acesso das políticas sanitárias às zonas rurais ocorreu somente na metade da década de 1910, com a instituição do Departamento Nacional de Saúde Pública (DNSP), dirigido pelo médico Carlos Chagas (COTTA et al., 2013, p. 93). Salienta-se que, nesse período, era possível identificar no Brasil a coexistência de três subsistemas paralelos, responsáveis pela implementação da denominada "Medicina Institucional", a saber: a) o sistema de "Saúde Pública", cuja aplicação prática se realizava mediante a instituição das políticas sanitárias destinadas, em tese, a toda população; b)o sistema de "Medicina do Trabalho" e; c) o sistema de "Medicina Previdenciária", sendo que esses dois últimos sistemas destinavam-se à assistência individual dos trabalhadores das zonas urbanas (COTTA et al., 2013, p. 93).

Tendo apresentado o delineamento institucional da saúde no contexto colonial e republicano, convém prosseguir historicamente a partir da primeira grande crise do capitalismo, ocorrida em 1920, que afetou a economia capitalista cafeeira, tendo sido capaz de redefinir a conjuntura institucional da Saúde Pública, na medida em que contribuiu para que a saúde fosse assumida como uma questão social de dever do Estado.

Constata-se, portanto, que essa crise afetou não só o cenário econômico, tendo repercutido também de modo significativo no contexto social dos trabalhadores urbanos, por meio do descontentamento com suas condições de saúde laboral, fato incitador de lutas, promovidas por esses segmentos sociais de classe, que resultaram em relativos avanços quanto à regulamentação do que, mais adiante, constituirá uma base para a emergência do que se entende por Previdência Social. Assim, em 1923, a Lei Eloy Chaves foi um importante instrumento regulamentador da formação de Caixas de Aposentadoria e Pensões (CAPs) para os trabalhadores urbanos (COTTA et al., 2013, p. 94).

\footnotetext{
Vale ressaltar que a lei beneficiou somente o operariado urbano. Para que fosse aprovada no Congresso Nacional, dominado na sua maioria pela oligarquia rural, foi imposta a condição de que esse benefício não seria estendido aos trabalhadores rurais - fato que na história da previdência do Brasil perdurou até a década de 1960, quando foi criado o FUNRURAL (COTTA et. al., 2013, p. 94).
}

A política pública de saúde permaneceu, portanto, exclusivamente, voltada para as cidades, relegando aos trabalhadores da zona rural, cerca de trinta anos de espera quando à implementação de um fundo social, operado nos moldes de um seguro, que os abarcasse. 
Além disso, curioso observar que embora a crise socioeconômica, vivenciada nos anos 20, tenha sido apresentada nesse estudo como desencadeadora do remodelamento institucional da saúde pública e, mais especificamente, como incitadora da ênfase institucional da saúde, enquanto política atribuída eminentemente ao Estado, pode-se dizer que os tímidos avanços identificados, nesse período, não resultaram efetivamente num agir eminentemente estatal sobre a saúde, uma vez que a própria criação do seguro social implementado pelas CAPs consistiu na implementação deum fundo tripartite alimentado por contribuições de trabalhadores, empregadores e consumidores de serviços da empresa organizadora do fundo, ou seja, sem a contribuição do Estado. No entanto, é importante reconhecer que (COTTA et al., 2013, p. 95) (BAPTISTA, 2008, p. 36)

\begin{abstract}
Apesar de o Estado não ter definido um sistema de proteção abrangente e de terse mantido fora dessa forma de organização privada, restringindo-se a legaliza-la e a controlá-la à distância, esse modelo serviu de base para a constituição de um primeiro esboço de sistema de proteção social no Brasil que se definiu a partir dos anos 1930 no governo do então presidente da república do Brasil, Getúlio Vargas.
\end{abstract}

\title{
3 O MOVIMENTO HISTÓRICO DA SAÚDE DO PERÍODO GETULISTA AO GOLPE DE 1964
}

Foi sob a vigência do governo de Getúlio Vargas e, mais precisamente, em 1933, que as CAPs foram substituídas pelos Institutos de Aposentadorias e Pensões (IAPs), os quais assumiram uma incidência mais abrangente quando comparados aos seguros que os antecederam (ESCOREL; TEIXEIRA, 2012, p. 279-322).

Tais institutos foram criados por Getúlio Vargas ao longo dos anos 30, favorecendo as camadas de trabalhadores urbanos mais aguerridas em seus sindicatos e mais fundamentais para a economia agroexportadora até então dominante. Ferroviários, empregados do comércio, bancários, marítimos, estivadores e funcionários públicos foram algumas categorias assalariadas favorecidas pela criação de institutos (LUZ, 1999, p. 79).

Nesse sentido, todas as categorias organizadas de trabalhadores urbanos passam a gozar os benefícios previdenciários, marco relevante para o início do arcabouço institucional do "Sistema Público de Previdência Social” (COTTA et al., 2013, p. 97). 
No entanto, esse marco não foi capaz de oferecer respostas às desigualdades sociais existentes e, mais especificamente, aos trabalhadores informais, que juntamente aos rurais, permaneceram socialmente marginalizados e destituídos de proteção, uma vez que, o benefício assegurado pelos IAP“eseram usufruídos apenaspor aqueles que efetivamente contribuíram com o seguro (COTTA et al., 2013, p. 93). Nesse ponto, merece menção as reflexões teóricas apresentadas por Sonia Fleury e Assis Ouveney ao tratarem da importância de se identificar a modalidade de proteção social adotada pelo país para a compreensão das implicações políticas resultantes do sistema implementado (FLEURY, 2008, p. 23-64).

Os autores advertem a necessidade de analisar uma política social de saúde tendo em vista não o beneficio adquirido, mas o "status" atribuído a concessão desse benefício e a consequente configuração do modelo de cidadania atribuído a esse contexto (FLEURY, 2008,p. 9).

Sob esse prisma analítico, considerando os apontamentos históricos delineados até então, é possível identificar na instituição dos IAPs um sistema de proteção pautado no modelo de seguro-social, destinado a grupos ocupacionais unidos por uma relação contratual, orientados sob uma lógica de proporcionalidade direta segundo a qual "[...] quanto maior a contribuição, maior o benefício" (FLEURY, 2008, p. 23-64). Sob essa ótica de análise, ressalta-se que o acesso à saúde corresponde a “[...] um benefício adquirido mediante pagamento prévio" e não a um direito de cidadania assegurado universalmente (FLEURY,2008, p 1; p. 12) (ESCOREL; TEIXEIRA, 2012, p. 279-322).

Esse modelo de sistema de proteção caracteriza-se, dentre outros elementos, por restringir a incidência da política social ao mercado de trabalho formal e permite que os destinatários dos benefícios sejam identificados segundo o "modelo de cidadania regulada", (ESCOREL, TEIXEIRA; 2012, p. 279-322) o qual alude “[...] à regulação exercida pela inserção de cada beneficiário na estrutura produtiva" (FLEURY, 2008, p. 13). Trata-se, pois, de uma concepção de cidadania necessariamente atrelada ao âmbito profissional devidamente regulamentada e definida pela lei (FLEURY, 2008, p. 13). Nesse ponto, tornase importante destacar o caráter excludente e discriminatório do modelo descrito, uma vez que os benefícios oferecidos por cada IAP dependia, em grande medida, da capacidade de contribuição e de organização das respectivas categorias profissionais . 
As categorias com maior poder econômico, como os industriais e os bancários, tinham maior disponibilidade de verbas e, por isso, podiam oferecer a seus contribuintes um leque maior de benefícios. No que diz respeito à saúde, um padrão melhor de assistência médica e hospitalar era oferecido, diferenciado por categoria e mantenedor da desigualdade social entre os trabalhadores (COTTA et al., 2013, p.99).

Foi no governo de Getúlio Vargas que ocorreu uma tentativa de alteração institucional quanto ao financiamento da previdência, uma vez que, estabeleceu-se o rompimento da relação direta entre empresa e caixa, a fim de que a União, e mais especificamente o Ministério do Trabalho, Indústria e Comércio, passasse a repassar as cotas dos consumidores para a Previdência (COTTA et al., 2013, p. 100). Entretanto, essa medida, na prática, não logrou êxito, culminando em um endividamento entre a União e a Previdência (COTTA et al., p. 100). Foi também durante a Era Vargas que foram criados o Ministério da Educação e Saúde Pública (MESP) (ESCOREL, TEIXEIRA, 2012, p. 301), responsável pela instituição de ações preventivas de saúde pública, e o Ministério do Trabalho, Indústria e Comércio (MTIC), um importante mecanismo institucional para a proteção da saúde dos trabalhadores, mediante a garantia de assistência médica individual previdenciária. Assim, (COTTA et. al.,2013, p. 100)

[...] Quem não se inseria na medicina previdenciária contava com alguns serviços ofertados pelo MESP em áreas estratégicas (saúde mental, tuberculose, hanseníase e outros), além da caridade e do assistencialismo dos hospitais e de profissionais de saúde. O MESP promovia também as ações de saúde pública, cuidando do controle e prevenção das doenças transmissíveis ainda nos moldes do sanitarismo campanhista.

No período em questão, as ações e serviços de saúde eram gozados pelos beneficiários da previdência, ao passo que os não beneficiários eram residualmente contemplados por ações e serviços de saúde pública preventiva, bem como pelas medidas de caridade que lhes fossem dispensadas. A saúde pública, embora desempenhada pelo Estado, não constituía um dever por parte do mesmo e nem um direito de cidadania a ser gozado e exercido pelos usuários. 
É interessante observar que o período getulista deixou como marca a separação entre saúde pública e a assistência médica previdenciária. A saúde pública era destinada a controlar e erradicar doenças infectocontagiosas que atingiam a população como um todo e estava direcionada a solucionar os problemas da coletividade. [...] A lógica das práticas sanitárias deste período se caracterizou, portanto por ações verticalizadas, centralizadas e emergenciais e que permaneceu por longos anos influenciando sobremaneira o desenho e a formulação do Sistema Nacional de Saúde Brasileiro (COTTA et al., 2013, p. 101-102, grifo nosso).

Trata-se, portanto, de um modelo pautado numa concepção de políticas públicas de saúde centradas na prevenção de enfermidades, na cura de doenças infecciosas, na noção de saúde como ausência de doença (COTTA el al., 2013, p. 18). Essa perspectiva, na prática, mostra-se insuscetível de contemplar, de modo abrangente, as necessidades básicas da população, tendo em vista os Determinantes Sociais em Saúde, bem como a melhoria da qualidade de vida e das condições materiais de existência dos sujeitos. Cumpre apontar algumas das características marcantes do modelo de saúde pública e das instituições de previdência social no período Getulista, valendo destacar que, ainda hoje, encontram-se resquícios dessas características na base das instituições responsáveis pela agenda, pela formulação e pela implementação das políticas públicas brasileiras.

Dessa forma, na primeira metade deste século podemos observar: centralismo, verticalismo e autoritarismo corporativo, do lado da saúde pública; clientelismo, populismo e paternalismo, do lado de instituições de previdência social, incluindo as de atenção médica. Estes traços, modelados durante cerca de cinqüenta anos, ainda são característicos das instituições e políticas de saúde brasileiras e integram a própria ordem política que se constituiu nesse período. É o próprio rosto de nossa estrutura social que se desenha sobre essa dupla face, ao menos no que esse rosto tem de mais atroz e recorrente em termos de poder (LUZ, 1999, p. 80, grifo do autor).

Em 1937, sob governança ditatorial de Vargas, o MESP passou por uma reforma organizacional, gerida por Gustavo Capanema, que culminou na nova denominação de Ministério da Educação e Saúde (MES), bem como na ampliação do Departamento Nacional de Saúde (DNS) visando assegurar maior interação entre os serviços locais e federais de saúde pública (COTTA et al., 2013, p. 101).

Outra instituição criada no período Varguista foi o Serviço Especial de Saúde Pública (SESP) (ESCOREL; TEIXEIRA, 2012, p. 303), como decorrência de uma cooperação entre os governos dos Estados Unidos e do Brasil, visando combater doenças nas áreas economicamente produtivas para os Estados Unidos em razão da produção da borracha e do café (COTTA et al., 2013, p. 101). Destaca-se que a criação do SESP e a 
finalidade para a qual suas ações se dirigiam apenas salientam o investimento da saúde pública em ações de medicina preventiva e curativa, tendo em vista a contenção emergencial de epidemias.

O governo que sucedeu o regime ditatorial Getulista (1937-1945) foi o de Eurico Gaspar Dutra (1946-1951), o qual assumiu a presidência da República num contexto de instabilidade política marcado pela ocorrência de movimentos grevistas de trabalhadores buscando a melhoria de suas condições laborais (COTTA et al., 2013, p. 102).

No âmbito da saúde pública, vivenciou-se a intensificação do modelo pautado no denominado "sanitarismo campanhista" (ESCOREL; TEIXEIRA, 2012, p. 305), marcado pelo autoritarismo na gestão emergencial das práticas sanitárias (COTTA et al., 2013, p. 102).

A partir de 1950, vivenciou-se, no Brasil, um contexto de crise econômica e instabilidade política decorrente das transformações sociais advindas da transição de uma economia predominantemente agrária para uma economia alicerçada no crescimento industrial (COTTA et al., 2013, p. 102-103). A década de 1950 foi marcada pelo fortalecimento do sistema de proteção à saúde, sobretudo em razão da ampliação do número de trabalhadores nos grandes centros urbanos, os quais usufruíam dos serviços de saúde por meio de convênios firmados com as empresas para as quais prestavam serviços (COTTA et al., 2013, p.103; p. 105). Nesse período, a lógica hospitalocêntrica ganha força estimulando o surgimento de grandes hospitais que prestavam serviços de saúde especializados com tecnologia de ponta. No entanto, é importante observar que

A tendência hospitalocênrica, baseada na ênfase em uma prática sanitária especializada, individualizada, médica e medicamentosa, não se restringia apenas ao Brasil, uma vez que o País seguia uma tendência mundial, fruto do conhecimento obtido pela ciência médica do pós-guerra (COTTA et al., 2013, p. 103).

Esta é uma importante observação no contexto de apresentação dos principais movimentos históricos que permitem compreender o modo como as políticas de saúde se desenvolveram no Brasil. Isso porque, a despeito de ser fruto das influências exógenas da medicina do pós-guerra, o investimento na prestação de serviços de saúde por grandes hospitais, assim como a ampliação do sistema de proteção social vivenciada a partir da década de 1950 não foi decorrência da adesão ao modelo político de Estado de Bem Estar 
Social, mas sim foi decorrência de uma conjuntura política orientada pela ideologia desenvolvimentista. Nesse sentido, afirma-se que

\begin{abstract}
No Brasil, ao contrário da política da Europa ocidental, não se estabeleceu nesse período (1951-1954), no segundo mandato de Getúlio Vargas, uma política de Estado de Bem-Estar Social, e sim uma ideologia desenvolvimentista (MATTA,2007), a qual considera que o nível de saúde de uma população depende primariamente do grau de desenvolvimento econômico de um país, sem se preocupar com o desenvolvimento social (COTTA et al., 2013, p. 103).
\end{abstract}

Nesse contexto desenvolvimentista, a saúde concebida enquanto política pública passa a ser debatida tendo em vista a "[...] utilização de técnicas e metodologias adequadas, importadas de outros países" (COTTA et al., 2013, p. 103-104).

Ainda nesse período, a previdência social, até então orientada pelo "modelo de seguro social”, passa a orientar-se pelo modelo de seguridade social (COTTA et al., 2013, p. 104). Essa alteração assume significativa importância na medida em que se esclarece que a proteção social assumida no modelo de seguridade pauta-se no compromisso de assegurar subsistência digna a todos os cidadãos, modificando substancialmente a concepção de justiça que orientará as políticas de saúde. Nesse sentido, afirma-se, conforme esclarece Fleury e Ouverney, que a proteção social assumida pela modalidade de seguridade social designa “[...] um conjunto de políticas públicas que inspiradas em um princípio de justiça social, garantem a todos os cidadãos o direito a um mínimo vital, socialmente estabelecido. [...] Nesse modelo, podemos falar de uma cidadania universal, já que os benefícios são assegurados como direitos sociais, de forma universalizada a todos aqueles que necessitem deles" (FLEURY; OUVERNEY, 2013, p. 104).

Apesar da alteração formal do modelo de proteção social adotado no país ter se constituído nesse período desenvolvimentista, é possível afirmar que sua consolidação ocorre apenas com a república democrática instituída com a Constituição Federal de 1988, a qual viabilizou mecanismos para a concretização do modelo assumido. Isso porque, conforme mencionado, no contexto da ideologia desenvolvimentista vigente, a saúde da população era aferida com base no desenvolvimento econômico alcançado pelo país e não pelo desenvolvimento social.

No ano de 1953, o Ministério da Saúde, até então atrelado ao Ministério da Educação (MESP), passa a ser gerido independentemente, (COTTA et al., 2013, p. 104) marco político representativo para o desenvolvimento das políticas de saúde no Brasil em 
razão da ênfase setorial proporcionada pela separação dos ministérios. Importante observar que [...] as políticas de saúde tornaram-se importantes ferramentas de Estado, uma vez que os recursos mobilizados para os postos de trabalho, indústrias de equipamentos e medicamentos, hospitais e ambulatórios foram significativamente elevados (MATTA, 2007).(COTTA et al., 2013, p.104).

No entanto, salienta-se que a ideologia desenvolvimentista que caracterizou o período e que foi responsável pelo crescimento econômico do país, pela modernização dos grandes centros urbanos, pela introdução das políticas de saúde como "ferramentas do Estado", não significou um comprometimento com a melhoria da qualidade de vida da população, sobretudo devido à falta de investimentos em ações direcionadas à prevenção e à promoção de saúde (COTTA et al., 2013, p. 104). Nesse período, não há que se falar, portanto, em política de saúde enquanto política social comprometida com a melhoria das condições materiais de existência dos cidadãos. Não houve uma política assumidamente de Estado que pautassem os investimentos e o desenvolvimento do setor.

\section{O MOVIMENTO HISTÓRICO DA SAÚDE DO GOLPE DE 1964 À REFORMA SANITÁRIA: AUTORITARISMO, CRESCIMENTO ECONÔMICO E PRIVATIZAÇÃO}

Em 1964, em razão do golpe militar, o desenvolvimento das políticas de saúde do Estado Brasileiro orientou-se pela permanência da assistência sanitária fundada na tendência hospitalocêntrica e pela ampliação da gestão privada dos recursos públicos (COTTA et al.,2013, p. 106).

Nesse período, os Institutos de Aposentadorias e Pensões (IAPs), criados no governo de Getúlio Vargas, foram unificados no Instituto Nacional de Previdência Social (INPS), fato que culminou num maior centralismo do poder no Estado e, consequentemente, no distanciamento dos trabalhadores do processo de tomada de decisão (COTTA et al., 2013, p.106-107). Além disso, a unificação dos Institutos foi prejudicial àqueles contribuintes que gozavam de mais benefícios na assistência à saúde, uma vez que estes também foram uniformizados e, em razão da demanda crescente de beneficiários, a qualidade da prestação dos serviços assegurados foi comprometida (COTTA et al., 2013, p. 106-107). 
O Sistema Nacional de Saúde vivenciou uma crise em razão da ineficiência do Sistema Previdenciário em assegurar melhor qualidade na assistência à saúde dos segurados, bem como em razão da retração financeira do Estado no que tange à prestação dos serviços de saúde. Nesse contexto, “[...] a „privatização ce da assistência médica previdenciária torna-se uma opção política dos governos dos regimes militares pós-64, uma vez que era necessário atender aos interesses de setores empresariais, importantes parceiros das elites dominantes" (COTTA et al., 2013, p. 107). Esse período também foi marcado pela falta de investimento em serviços de saúde pública preventiva e em promoção da saúde. Nesse sentido, as ações e serviços de saúde, prestados por hospitais privados orientados pela especialização, visavam à atenção individual e curativa, ao invés da coletiva e preventiva (COTTA et al., 2013, p. 108).

Aprofundando-se na historicidade das políticas de saúde no Brasil, no período de 1964 a 1990, Sarah Escorel realiza uma subdivisão temporal em quatro momentos: a) a primeira década do regime militar; b) o momento de retração do autoritarismo e de emergência do movimento da reforma sanitária; c) o ingresso de militantes da reforma sanitária no último governo militar no contexto de crise da previdência; c) a $8^{\mathrm{a}}$ Conferência Nacional, o processo Constituinte, a saúde concebida como um direito e assumida como política de Estado, alicerçada no Sistema Único de Saúde (ESCOREL, 2012, p. 323). Vivenciou-se, no período militar, um crescimento econômico traduzido na modernização do aparato estatal e no favorecimento da acumulação capitalista. Nessa ambiência,

Nesse período, foram criados o INPS (Instituto Nacional de Previdência Social), em 1966, o FGTS (Fundo de Garantia por Tempo de Serviço), em 1977, o PIS (Programa de Integração Social) e o PASEP (Programa de Formação de Patrimônio do Servidor Público), ambos em 1970 (ESCOREL, 2012, p. 326).

No contexto da previdência social, a partir de 1964, o modelo adotado pelo IAPI favoreceu o setor privado de serviços de saúde, sob o fundamento de incapacidade de fornecimento de assistência médica pela rede de serviços do INPS. De acordo com Escorel (2012, p. 327), "No caso da previdência, o INPS passou a ser o grande comprador de serviços privados de saúde e, dessa forma, estimulou um padrão de organização da prática médica orientado pelo lucro".

A despeito do crescimento do PIB, vivenciado no período do "milagre econômico", é importante observar que o quadro da saúde pública era instável e anunciador de uma crise, 
decorrente, dentre outros motivos, da insuficiência de recursos destinados ao ministério da saúde (ESCOREL, 2012, p. 329).

No que tange às tendências privatizantes nas políticas de saúde que marcaram o período, estas podem ser ilustradas, exemplificativamente, pelo Plano Nacional de Saúde (PNS), cuja pretensão consistia na venda de hospitais governamentais para a iniciativa privada, competindo ao Estado e aos pacientes a função de financiamento dos serviços disponibilizados. Trata-se, pois, de proposta suscitada pelo Ministério da saúde (ESCOREL,2012, p. 329). Se por um lado, o regime militar pode ser apontado como o período da reforma estatal que representou o marco para a privatização da saúde, por outro lado, foi também sob a égide do autoritarismo, mais precisamente no final da década de 60 e no início da década de 70, que as bases do movimento da Reforma Sanitária foram sedimentadas.

Esse movimento, fundado na medicina social, constituiu-se preliminarmente no âmbito acadêmico, especificamente nos departamentos de Medicina Preventiva (DMP) das faculdades de Medicina. Desse lócus emergiu, do ponto de vista teórico, como ideário "histórico-estrutural dos problemas de saúde" (ESCOREL, 2012, p. 330), o que posteriormente se consolidou, do ponto de vista simbólico, como movimento político, eminentemente, social. O projeto da Reforma Sanitária é a representação simbólica e prática de movimento social reivindicativo que no contexto da luta por democratização, no âmbito da saúde, foi responsável pela confrontação ao paradigma biomédico vigente nas políticas públicas de saúde (PAIM, 1997, p. 11).

Estimulados pela OPAS, bem como pela disseminação de programas de medicina comunitária, que geralmente eram vinculados aos DMPs, o modelo de saúde preventiva foi confrontado, suscitando a organização de segmentos engajados, no interior da universidade, voltados a estruturação de referenciais teóricos, no âmbito da saúde, responsáveis por viabilizar a percepção de "[...] padrões diferenciados de formação de recursos humanos" (ESCOREL, 2012, p. 332). Conforme esclarece Escorel, a partir da elucidação de Paim,

As três correntes de pensamento [...] podem ser divididas a partir da conceituação do social" em saúde: para o preventivismo, trata-se de um conjunto de atributos pessoais, como educação, renda, salário, ocupação etc.; para o modelo racionalizador, um coletivo de indivíduos; para a abordagem médicosocial, um campo estruturado de práticas sociais. 
Dito isto, convém observar que tais categorias analíticas são fundamentalmente importantes por suscitarem reflexões acerca das distintas concepções de saúde que alicerçaram o desenvolvimento das políticas públicas do setor ao longo dos movimentos históricos apresentados. A saúde, a partir da "abordagem médico-social" é concebida tendo em vista “[...] a prática política e a consciência sanitária como parte da consciência social, visando à transformação social" (ESCOREL, 2012, p. 333).

Ainda no contexto de repressão militar, na gestão do general Geisel, ressalta-se que a fase desenvolvimentista exitosa passou a ser tensionada por pressões sociais insatisfeitas com os problemas resultantes de crises econômicas tanto no âmbito nacional, quanto no internacional. (aumento da inflação, crescimento da dívida externa, o aumento do preços, o arrocho salarial, a especulação financeira, a retração da atividade produtiva) (ESCOREL,2012, p. 335-336).

A segunda metade da década de 1970, período em que o capitalismo internacional atravessou uma crise e que a desigualdade social e a concentração de renda foram as consequências dessa crise vivenciada pelo modelo econômico desenvolvimentista vigente desde a primeira gestão militar, foi marcada pela emergência de movimentos, tanto da sociedade quanto das classes dominantes, que se insurgiram contra a insuficiência do modelo de saúde previdenciário vigente visando à descentralização (COTTA et al., 2013.p.110).

O movimento político contrahegemônico da Reforma Sanitária, (FLEURY, 1997, p.11) ocorrido, no Brasil, na segunda metade da década de setenta, foi responsável por conceber a saúde criticamente rompendo com as matrizes teóricas que a sustentavam num conceito estritamente individualista e biológico e, assim, contribuindo significaticamente para que a transição epistemológica da saúde se concretizasse por meio da emergência do Constituição de 1988 (PAIM, 1997).

\footnotetext{
A Reforma Sanitária brasileira nasceu na luta contra a ditadura, com o tema Saúde e Democracia, e estruturou-se nas universidades, no movimento sindical, em experiências regionais de organização de serviços. Esse movimento social consolidou-se na $8^{\text {a }}$ Conferência Nacional de Saúde, em 1986, na qual, pela primeira vez, mais de cinco mil representantes de todos os seguimentos da sociedade civil discutiram um novo modelo de saúde para o Brasil. O resultado foi garantir na Constituição, por meio de emenda popular, que a saúde é um direito do cidadão e um dever do Estado. (AROUCA. 1998).
} 
Sobre a emergência do movimento e a consolidação de suas matrizes, convém destacar que transformação na orientação governamental, no âmbito da saúde, deu-se paralelamente a assunção de cargos de gestão por militantes da reforma sanitária, tais como Sérgio Arouca, que assumiu a presidência da Fundação Oswaldo Cruz, e Hésio Cordeiro, que presidiu o Inamps (Instituto Nacional de Assistência Médica da Previdência Social) (ESCOREL, 2012, p. 356).

A $8^{\text {a }}$ Conferência Nacional de Saúde foi incitada numa ambiência de resistência e irresignação ante os problemas atinentes ao setor saúde, tendo resultado enérgicos embates responsáveis por promoverem uma alteração institucional significativa, consolidando os pressupostos norteadores na Política Nacional de Saúde (FANTON, 2014). Essa conferência viabilizou a constituição da Comissão Nacional da Reforma Sanitária (CNRS), a qual elaborou a proposta do capítulo da saúde na constituição de 1988 (ESCOREL, 2012, p. 357-358). Nessa conjuntura, a Constituição de 1988 representou o marco paradigmático no âmbito da ampliação da concepção de saúde, na medida em que instituiu o Sistema Único de Saúde e definiu a saúde, em seu art. 196 e seguintes, como um direito universal e igualitário, abrangendo em seu âmbito de efetivação a promoção, a proteção e a recuperação (COTTA et al., 2013, p. 28).

A essa ordem constitucional democrática associa-se o paradigma da produção social da saúde, modelo centrado no ser humano que se pautava na concretização de ações políticas suficientemente aptas a oferecer respostas aos compromissos sociais assumidos que restaram frustrados, no final da década de oitenta, com a Crise do chamado Estado de Bem Estar Social (COTTA et al., 2013, p. 78-79). Nesse contexto, a produção social da saúde implica em considerá-la, para além da cura de doenças, enquanto “[...] ações políticas para a redução de desigualdades, educação, cooperação intersetorial, participação da sociedade civil nas decisões que afetam a sua existência [...]" (SANTOS; WESTPHAL, 1999, p. 76).

No entanto, a despeito da força propulsora, incitada pelo movimento da Reforma Sanitária, e de todos os significativos e inegáveis avanços decorrentes as lutas assumidas, as lacunas deixadas pelo texto constitucional no que tange ao marco regulatório da relação público/privado no contexto do Sistema Único de Saúde (SUS), remontam a questionamentos atinentes ao esvaziamento substancial dos compromissos constitucionalmente assumidos com a saúde. 


\begin{abstract}
De maneira mais geral, o vazio institucional e a ausência de um marco regulatório referente às relações entre o público e o privado no Sistema Único de Saúde garante a ausência de controle público sobre o setor privado. Este não só segue existindo como é dependente dos recursos públicos, por mecanismos como o acesso a financiamentos de Fundos Públicos; permanentes renúncias fiscais; venda de planos de saúde ao funcionalismo; isenções tributárias; dupla porta de entrada em hospitais públicos (que permite atendimento diferenciado nos hospitais públicos a clientes de planos de saúde); renúncia fiscal de pessoas físicas e jurídicas nas declarações de imposto; e o não ressarcimento do Estado pelo atendimento dos clientes da iniciativa privada na rede pública (FANTON, 2014).
\end{abstract}

Tais constatações, perceptíveis pelos desdobramentos contemporâneos da orientação das políticas públicas de saúde no Brasil, impõem novas alternativas de resistência e por que não dizer uma ressig nificação do ativismo e da militância ante a conjuntura posta.

Dentre os anúncios de retrocessos identificados no momento histórico pós- Constituição de 1988, ressalta-se que a “[...] criação de fundos de estabilização fiscal permitiu a desvinculação de receitas da União que constitucionalmente deveriam ser voltadas para políticas sociais". (FANTON, 2014). Além disso, nos anos de 1995-2002, o Plano Diretor de Reforma do Aparelho do Estado (PDRAE) alicerçou a transferência de recursos públicos por meio de Organizações Sociais da Saúde (OSS) (FANTON, 2014). Esse é ponto a partir do qual promover-se-á um breve aprofundamento no contexto da relação público/privado, convidando o leitor a problematizar as consequências da festão privada de recursos públicos para a orientação das políticas públicas de saúde no país.

\title{
5. A SAÚdE NO CONTEXTO DA RELAÇÃO PÚBLICO-PRIVADO: CONSEQUÊNCIAS DA GESTÃO PRIVADA DE RECURSOS PÚBLICOS PARA A ORIENTAÇÃO DAS POLÍTICAS PÚBLICAS DE SAÚDE NO BRASIL
}

O interesse em aprofundar os estudos acerca de políticas públicas de saúde decorre, em primeiro lugar, da importância de se (re)pensar os desafios inerentes a contextualização das políticas públicas de saúde no contexto da democracia brasileira não consolidada.

Nesse contexto, a compreensão do processo histórico de construção da acepção de saúde, e de sua ampliação, no Brasil assume sua relevância por estar diretamente atrelada ao modo como as práticas sanitárias e as políticas públicas, visando à promoção da saúde, irão se desenvolver. Daí porque compreender a concepção de saúde que tem alicerçado o 
desenvolvimento dos segmentos produtivos do setor saúde pressupõe sua contextualização na conjuntura de transformações resultantes da hegemonia do sistema capitalista.

Trata-se de assunto bastante debatido doutrinariamente, o que, neste ponto de vista, representa um aspecto positivo, pois estimula o debate e a consequente reformulação de estratégias para que (re)pensemos, no âmbito das políticas públicas de saúde, alternativas e possibilidades de resistência ante a força dinâmica dos fluxos do capital.

As desigualdades e exclusões que (des)caracterizam a sociedade brasileira, cada vez mais, tem se agravado pelas novas estratificações sociais produzidas pela reestruturação produtiva, bem como pelos efeitos do progressivo desmantelamento dos serviços públicos, culminando no afastamento do Estado da responsabilidade social que lhe foi, constitucionalmente, atribuída (TELLES, 1999, p. 35).

Diante desse quadro, a lógica empresarial capitalista não deve ser vislumbrada tão somente enquanto circunstância caracterizadora de um cenário de intensificação de crises, mas, além disso, deve ser compreendida como um componente fundamental que passou a integrar o sistema de saúde, materializando redes de interações com o mesmo que tem sido capazes de interferir significativamente em diversos segmentos produtivos (GADELHA,2003, p. 522).

Trata-se, pois, de uma perspectiva analítica que demonstra o quão indissociável do setor saúde é o "processo de penetração do capital e empresariamento", daí porque Carlos Augusto Grabois Gadelha ao delimitar o que nominou "complexo industrial da saúde" assegura que o setor saúde, visceralmente atrelado à lógica empresarial capitalista, deve ser percebido enquanto "[...] conjunto interligado de produção de bens e serviços em saúde que se movem no contexto da dinâmica capitalista" (GADELHA, 2003, p 523).

A partir da apresentação do contexto de inter-relações entre organizações e instituiçõos privadas e os órgãos e as políticas públicas, buscar-se-sá compreender o processo de construção da concepção de saúde que tem sustentado as práticas sanitárias e, até mesmo, as políticas públicas que visam à promoção da saúde, repercutindo no modo como estas tem se desenvolvido.

Destaca-se, neste estudo, que, no âmbito da relação público-privado, a gestão de recursos públicos realizada por Organizações Sociais de Saúde (OSs) apresenta-se como decorrência de movimentos fundamentalmente atrelados à onda de reformas do Estado que tem interferido na natureza eminentemente pública de serviços e de atividades, na medida em que tem propiciado a sedimentação de “[...] um conjunto de inovações 
organizacionais” tal qual a criação de organismos públicos não estatais (GADELHA, 2003, p. 522).

O debate acerca da orientação das políticas públicas de saúde no Brasil tem se seguido dessa constatação de interação mercadológica marcada por “[...] relações de contratualização e de constituição de quaismercados, além de um conjunto de inovações organizacionais [...]" que “[...] passam a pressionar os agentes para seguirem lógicas de obtenção de competitividade e de eficiência econômica em suas atividades" (GADELHA, 2003, p. 522).

Nesse contexto, pretende-se confrontar a concepção de saúde constitucionalmente adotada com a concepção de saúde que tem alicerçado, a partir de uma lógica tipicamente empresarial, o desenvolvimento dos segmentos produtivos do setor. O que está em discussão, portanto, é a natureza jurídica da concepção de saúde: ou seja, se seria a saúde um "bem público", um "bem de consumo" ou um "direito universal”?

Tensionar conceitos de mercado/comércio no âmbito do setor saúde é um exercício que ultrapassa a ideia de "mercadorização", isto é, a constatação de que há mercado na saúde. Para além disso, esse tensionamento tem em vista uma perspectiva analítica pautada nos fluxos de capital e na influência destes no conjunto de atividades, serviços e interações relacionadas à saúde.

Nesse sentido, importante observar que nos estudos de Gadelha (2003) acerca do Complexo Econômico Industrial da Saúde essa interação saúde-mercado é vislumbrada positivamente uma vez que, segundo o autor, o sistema de saúde está inserido nesse "sistema econômico produtivo interdependente" que opera na economia brasileira, correspondendo a 10\% do Produto Interno Bruto (PIB) do país (GADELHA, 2013). Portanto, o sistema de saúde já não existe sem a indústria, embora haja autores que discordem dessa assertiva por encararem a interação saúde-mercado de um modo não virtuoso. Nas palavras de Gadelha “O CEIS é um projeto nacional de soberania e para dotar o Brasil de condições tecnológicas para tornar o SUS protegido do mercado mundial" (GADELHA, 2013).

A dinâmica do capitalismo é pautada na lógica lucrativa do maior retorno e a reforma gerencial do Estado, compreendida como corolário deste dinamismo, fomentou a criação de organismos não estatais que passaram a desempenhar gestão de serviços, de recursos, de atividades eminentemente públicas, a exemplo das Organizações Sociais de 
Saúde (OSs) que, inclusive, circunscrevem-se no corte metodológico realizado por esta pesquisa.

As Organizações Sociais de Saúde (OSs) se transformaram numa alternativa para a administração pública que tem desmantelado o público e, consequentemente, precarizado o Sistema Único de Saúde (SUS) que, por sua vez, na correlação de forças que a lógica empresarial capitalista impõe, tem sofrido com as deslegitimações discursivas, por parte de seus usuários e servidores, bem como com as práticas depreciativas incestuosas que passaram a o envolver, a exemplo da flexibilização das relações de trabalho decorrente das privatizações setoriais frequentemente incorporadas pelo setor e legalmente amparadas com a aprovação do projeto de lei n. ${ }^{\circ}$ 4330/2004.

Uma importante distinção que merece destaque é a diferenciação das "políticas de desenvolvimento produtivo" das "parcerias público privadas", uma vez que aquelas, previstas no CEIS, consistem na transferência da gestão, do serviço, da atividade ao privado sem que, no entanto, haja transferência do domínio da tecnologia. Nas palavras do autor, nessas "políticas de desenvolvimento produtivo" o "[...] desenvolvimento tecnológico é compartilhado entre as instituições públicas, os parques tecnológicos, as universidades e o setor privado. Isso é desenvolvimento em conjunto e não apenas uma comercialização da produção" (GADELHA, 2013).

Nota-se que a construção de uma base empírica suficientemente capaz de promover análises das consequências dessa gestão, realizada por organismos não-estatais, para a compreensão da concepção de saúde que tem norteado o desenvolvimento das políticas públicas não implica necessariamente numa crítica maniqueísta direcionada à associação saúde-mercado tão somente em razão da afirmação de um posicionamento ideológico assentado na afirmação do público em detrimento do privado.

Trata-se, para além disso, do desafio de contextualizar a saúde no enquadramento do mercado a fim de confrontar, dialeticamente, suas bases de sustentação a partir da identificação das principais ações/relações/interações que se ocultam nas estruturas das organizações sociais de saúde (Oss), tendo em vista a dinâmica do complexo econômico industrial da saúde (Ceis). Com isso, questiona-se se o sistema de saúde, de fato, é uma indústria e se, no Brasil, a relação dos elementos duros do capitalismo podem ser domados. Daí a necessidade de se produzir conhecimento para, assim, contribuir para a elaboração de estratégias políticas com esse fim. 
$\mathrm{O}$ tratamento dispensado às questões-problema incitadas por este breve estudo tem em seu pano de fundo o despertar das possibilidades de resistência frente a selvageria do capital que perversamente tem alicerçado as práticas no âmbito da saúde, fragilizando, cada vez mais, a consolidação da concepção de saúde que sustentou o contexto sociopolítico instituído com a Constituição Federal de 1988.

\section{CONSIDERAÇÕES FINAIS}

Os desdobramentos decorrentes da percepção do pano de fundo sociopolítico que respalda o imaginário social coletivo, no que tange ao direito à saúde, são produtos de uma realidade mercadológica fomentadora de discursos que, não raras vezes, deslegitimam a função precípua do Estado em viabilizar e efetivar a saúde enquanto dever de implemento de política social. Daí porque compreender a concepção que tem alicerçado o desenvolvimento dos segmentos produtivos do setor saúde pressupõe sua contextualização na conjuntura de transformações resultantes da hegemonia do sistema capitalista.

Esta pesquisa se propôs a adentrar o contexto das transformações resultantes da hegemonia do sistema capitalista para questionar, no âmbito da relação público-privado, as consequências da gestão privada de recursos para a concepção de saúde que tem orientado as políticas públicas de saúde no Brasil. A concepção de saúde constitucionalmente adotada parece não se coadunar com a concepção de saúde que tem alicerçado o desenvolvimento dos segmentos produtivos do setor, daí a necessidade de se promover análises de conjuntura que permitam compreender, a partir da macro política, os rumos a que se dirigem as políticas de saúde no país.

Nesse sentido, salutar é o compromisso político e ideológico propiciada por uma ambiência acadêmica comprometida com a realização de relevantes intervenções sociais. Esse é o alicerce indispensável para o estímulo à resistência ativa, interventora e, por que não dizer, cidadã ante aos retrocessos vivenciados contemporaneamente. 


\section{REFERÊNCIAS BLIBLIOGRAFICA}

AROUCA, Sérgio. Saúde na constituinte: a defesa da emenda popular. Saúde em debate, n. 20, p. 36-46, abr., 1988.

BAPTISTA, Tatiana Wargas de Faria. História das políticas de saúde no Brasil: a trajetória do direito à saúde. Disponível em: http://webcache.googleusercontent.com/search?q=cache:LTjGz8v_I-gJ:https://ufrr.br/proci sa/index.php\%3Foption\%3Dcom_phocadownload\%26view\%3Dcategory\%26download\%3 D187:historia-politicas-saude-tatiana ptista\%26id\%3D29:textos\%26Itemid\%3D275+\&cd=1 $\& \mathrm{hl}=\mathrm{pt}-\mathrm{BR} \& \mathrm{ct}=\mathrm{clnk} \& \mathrm{gl}=\mathrm{br}$. Acesso em: $11 \mathrm{dez} .2015$.

ESCOREL, Sarah; TEIXEIRA, Luiz Antonio. História das política de saúde no Brasil de 1822 a 1963: do império ao desenvolvimentismo populista. In: GIOVANELLA, Ligia et al. (Orgs.). Políticas e sistemas de saúde no Brasil. Rio de Janeiro: Editora Fiocruz, 2012. p. 279-322.

ESCOREL, Sarah. História das políticas de saúde no Brasil de 1964 a 1990: do golpe militar à reforma sanitária. In: GIOVANELLA, Ligia et al. (Orgs.). Políticas e sistemas de saúde no Brasil. Rio de Janeiro: Editora Fiocruz, 2012. p. 323-363.

FANTON, Hugo. Hugo Fanton: a saúde e a luta por uma Constituinte exclusiva. Cebes: Centro Brasileiro de Estudos de Saúde, set., 2014. Disponível em: http://cebes.org.br/2014/09/a-saude-e-a-centralidade-da-luta-por-uma-constituinteexclusiva/. Acesso em: 26 jan. 2016.

FLEURY, Sonia; OUVERNEY, Assis Mafort. Política de saúde: uma política social. In: GIOVANELlA, Lígia et al. (Org.). Políticas e sistema de saúde no Brasil. Rio de Janeiro: Ed. Fiocruz, 2008. 13.

GADELHA, Carlos Augusto Grabois. Desenvolvimento e saúde: em busca de uma nova utopia. Saúde Debate,v. 29, p. 327-38. 2007.

GADELHA, Carlos Augusto Grabois. O complexo industrial da saúde e a necessidade de um enfoque dinâmico na economia da saúde. Ciência Saúde Coletiva, v. 8, p. 521-35. 2003. COTTA, Rosângela Minardi Mitre et al. Políticas de saúde: desenhos, modelos e paradigmas. Viçosa-MG: Editora Ufv, 2013.p. 89.

GADELHA, Carlos Augusto Grabois. O investimento no complexo Industrial da saúde e a melhoria das desigualdades em saúde. 2013. Disponível em: http://dssbr.org/site/entrevistas/o-investimento-no-complexo-industrial-da-saude-e-amelhoria-das-desigualdades-em-saude/. Acesso em: 06 out. 2015.

LUZ, Madel Therezinha. Notas sobre as políticas de saúde no Brasil de "Transição democrática": anos 80. Physis: revista de Saúde Coletiva, v. 1, n. 1, 1991. Disponível em: http://www.scielo.br/pdf/physis/v1n1/04.pdf. Acesso em: 11 dez. 2015. 
PAIM, Jairnilson. Bases conceituais da Reforma Sanitária Brasileira. In: FLEURY, Sonia. Saúde e democracia: a luta do Cebes. São Paulo: Lemos, 1997.

SANTOS, Jair Lício Ferreira; WESTPHAL, Marcia Faria. Práticas emergentes de um novo paradigma de saúde:o papel da universidade. Estudos avançados, v.13, n. 35, pp. 71-88, 1999. Disponível em: http://www.scielo.br/scielo.php?script=sci_arttext\&pid=S010340141999000100007. Acesso em: $11 \mathrm{dez} .2015$.

TELLES, Vera da Silva. Direitos sociais: afinal do que se trata? Revista USP, São Paulo, n. 37, p. 34-45, mar./maio, 1998. Disponível em: http://www.usp.br/revistausp/37/04-vera.pdf. Acesso em: 05 out. 2015 